\title{
Palmitoleik Asidin Bazı Kronik Hastalıklardaki Rolü: Kısa Derleme
}

\author{
Mahmut BODUR ${ }^{1}{ }^{1}$, Aslı UÇAR [i] $^{1}$
}

\begin{abstract}
Öz
Günümüzde obezite, dislipidemi, kardiyovasküler hastalıklar, tip 2 diyabet gibi kronik hastalıkların görülme sıklı̆̆ı artmaktadır. Diyet örüntüsünün kronik hastalıkların oluşumu ve ilerlemesindeki rolü iyi bilinmektedir. Yeterli ve dengeli bir diyette bulunması gereken en önemli parçalardan birisi, besinlerle alınan yağlardır. Özellikle son yıllarda diyetle alınan toplam yağ miktarının yanı sıra farklı yağ asitlerinin rolü üzerinde durulmaktadır. Bu yağ asitlerinden biri olan palmitoleik asit on altı karbonlu, tekli doymamış bir yağ asididir. Palmitoleik asit, başlıca adipoz doku ve karaciğerde metabolize olmaktadır. Vücutta bulunan miktarları doku ve bölgeye spesifik olarak değişmektedir. Bununla birlikte, palmitoleik asidin bazal konsantrasyonları metabolik süreçlere bağlı olarak değiş̧im göstermektedir. Bu nedenle palmitoleik asidin adipoz dokudan salınan bir "lipokin" olabileceği ve palmitoleik asit metabolizmasının kronik hastalıkların önlenmesinde etkili olabileceği düşünülmektedir. Palmitoleik asidin etkilerini açıklamak için daha kapsamlı kohort, longitudinal ve randomize kontrollü çalışmalara ihtiyaç bulunmaktadır. Bu derlemede obezite, tip 2 diyabet, kardiyovasküler hastalıklar gibi kronik hastalıkların oluşumunda palmitoleik asit takviyesinin olası rolü güncel çalışmalar eşliğinde incelenmiştir.
\end{abstract}

Anahtar Kelimeler: Dislipidemiler; diyet yağları; obezite.

\section{Palmitoleic Acid and its Role in Certain Chronic Diseases: A Brief Review}

\begin{abstract}
In recent years, the incidence of chronic diseases such as obesity, dyslipidemia, cardiovascular diseases, type 2 diabetes is increasing. The role of dietary pattern in the emergence and progression of chronic diseases is well known. One of the most important parts of a sufficient and balanced diet is the fat taken with food. Especially in recent years, the role of different fatty acids as well as the total amount of fat taken with diet has been focused on. Palmitoleic acid, one of these fatty acids, is a sixteen-carbon, monounsaturated fatty acid. Palmitoleic acid is metabolized mainly in adipose tissue and liver. The amount found in the body varies specifically for the tissue and the region. However, basal concentrations of palmitoleic acid vary depending on metabolic processes. Therefore, palmitoleic acid is thought to be a "lipokine" released from adipose tissue and palmitoleic acid metabolism may be effective in preventing chronic diseases. More comprehensive cohort, longitudinal and randomized controlled studies are needed to explain the effects of palmitoleic acid. In this review, the possible role of palmitoleic acid supplementation in the formation of chronic diseases such as obesity, type 2 diabetes and cardiovascular diseases was examined in the light of recent studies.
\end{abstract}

Keywords: Dyslipidemias; dietary fats; obesity.

\section{GíRiş}

Günümüzde kronik hastalıkların görülme sıklığı giderek artmaktadır ve bu nedenle kronik hastalıkların önlenmesi ve tedavisi halk sağlığı politikalarının öncelikleri arasında yer almaktadır. Obezite, tip 2 diyabet, metabolik sendrom, kardiyovasküler hastalıklar gibi kronik hastalıkların patofizyolojik mekanizmalarının anlaşılması bu hastalıkların önlenmesinde yol göstericidir. Dünya Sağlık Örgütü (DSÖ) verilerine göre bulaşıcı olmayan kronik hastalıkların ortaya çıkmasında temel nedenler arasında yetersiz beslenme, fiziksel inaktivite, tütün ve alkol kullanımı yer almaktadır $(1,2)$.

1 Ankara Üniversitesi, Sağlık Bilimleri Fakültesi, Beslenme ve Diyetetik Bölümü, Ankara, Türkiye 
Özellikle son yıllarda yeterli ve dengeli beslenmenin kronik hastalıkların ve bu hastalıklara bağlı olarak gelişen komplikasyonların önlenmesindeki rolü önem kazanmaktadır.

Diyette yer alan karbonhidrat, yağ ve proteinler günlük alınan toplam enerjinin en önemli kısmını oluşturan makrobesin ögeleridir (3). Diyette yağdan gelen enerji miktarının, kronik hastalıkların oluşumundaki etkisine ek olarak, diyetle alınan yağ asidi örüntüsünün de aslında çok önemli olduğu ve vücutta gerçekleşen birçok metabolik yolakta etkin olabileceği saptanmıştır (4). Ulusal ve uluslararası beslenme rehberleri doymuş yağ asitlerinin (SFA) alımının azaltılmasını önerirken, diyetteki tekli doymamış yağ asitleri (MUFA) ve çoklu doymamış yağ asitleri (PUFA) miktarını artırmayı önermektedir (3-5). Tekli doymamış yağ asitleri olarak diyette oleik asit ön plana çıkarken, palmitoleik asit güncel çalışmalarda üzerinde sıklıkla durulan bir diğer yağ asididir $(6,7)$.

Palmitoleik asit, 16 karbonlu, 7. C atomunda çift bağ içeren bir tekli doymamış yağ asididir (7). Palmitoleik asidin, diyetle alımının yanı sira endojen sentezi ve kronik hastalıklardaki yüksek serum konsantrasyonları, yapılan çalışmaların temelini oluşturmaktadır. Obezite, tip 2 diyabet ve kardiyovasküler hastalıklarda serum palmitoleik asit konsantrasyonları sağlıklı bireylere kıyasla daha yüksek bulunmuştur $(6,8)$. Başlıca karaciğerde ve adipoz dokuda metabolize olan palmitoleik asit, adipoz doku, eritrosit, hücre zarı gibi birçok farklı bölgede bulunabilmektedir $(9,10)$. Kronik hastalıklara bağlı olarak dolaşımdaki değişen konsantrasyonları, bazal seviyesinin düşük konsantrasyonlarda bulunması ve adipoz doku, karaciğer, kas gibi farklı dokular üzerinde farklı metabolik yanıtlar oluşturmasına bağlı olarak palmitoleik asit bir lipokin olarak adlandırılmakta ve güncel çalışmalarda bu rolü üzerinde durulmaktadır (11). Ancak kronik hastalıklar üzerindeki etkilerini gösteren çalışmalar az sayıdadır. Bu nedenle bu derleme çalışmanın amacı, palmitoleik asidin sağl1k üzerine etkileri ve obezite, tip 2 diyabet, kardiyovasküler hastalıklar gibi kronik hastalıklardaki olası rolünü güncel çalışmalar eşliğinde incelemektir.

\section{Diyet kaynakları}

Palmitoleik asit, cis ve trans formlarında olup alınan toplam enerjinin \%4'ünden daha azına katkı vermektedir. Kan lipit havuzunda en yaygın bulunan 2. tekli doymamış yağ asidi olarak öne çıkmakta, ancak günlük diyette düşük miktarlarda bulunmaktadır (7). Belirgin olarak bulunduğu bir besin olmamakla birlikte diyet kaynakları arasında somon (\%6/100 g yağ asitleri), morina karaciğer yağ1 $(\% 7 / 100$ g yağ asitleri) ve makademya yağ (\%17/100 g yă asitleri) yer almaktadır (12). Yalancı iğde olarak bilinen hippophae rhamnoidesinde iyi bir palmitoleat kaynağ 1 olduğu gösterilmektedir ve özellikle Asya bölgesinde kullanıldığı bildirilmektedir (13). Transpalmitoleatın diyet kaynaklarında ise kısmi hidrojenize yağlar ve süt ürünleri bulunmaktadır (14).

\section{Endojen Palmitoleat Sentezi}

Diyet kaynaklarının kısıtlı olması ve hızlı okside olması palmitoleik asidin endojen sentezinin önemini göstermektedir. Palmitoleik asit, insanlarda başlıca palmitat ve oleik asitten endojen de novo lipojenez ile sentezlenmektedir. Tekli doymamış yağ asitlerinin sentezinde hiz kisitlayıcı basamakta yer alan stearil Co-A desatüraz-1 (SCD-1) enzimi palmitoleik asidin sentezinde de görev almaktadır. Metabolizması oleik asitle benzerlik gösteren palmitoleik asit, hızlı bir şekilde dokulara geçiş yaparak burada nötral yağların bileşiminde yer almaktadır (15).

Cis-palmitoleik asidin yanısıra vücutta düşük konsantrasyonlarda trans-palmitoleik asidinde endojen sentezinin olduğu bildirilmektedir. Diyetle alınan vakkenik asitin (18:1t11) zincir kısalması ile \%17 oranında trans-palmitoleik aside dönüştüğü saptanmıştır (16). Insanlarda cis-palmitoleat biyosentezi başlıca karaciğerde ve ikincil olarak da adipoz dokuda gerçekleşmektedir. Adipoz dokuda palmitoleik asit, fosfolipidler, trigliseritler, waxlar ve kolesterol esterleri gibi kompleks lipitlerin kompozisyonlarında bulunabilmektedir. Bununla birlikte palmitoleik asidin plazma trigliseritleri, plazma fosfolipitleri, plateletler, kırmızı kan hücreleri ve adipoz dokuda bulunan yağ asitleri içerisindeki miktarı \%0,4-5,2 arasında değişebilmektedir $(9,10)$. Palmitoleik asit miktarlarının bulunduğu dokuya özgü olarak da değişkenlik gösterdiği saptanmıştır. Üst kol ve uyluktaki subkutanöz adipoz dokudaki palmitoleik asit seviyeleri, abdominal subkutanöz yağlardan daha yüksektir.

\section{Sağlık üzerine etkileri}

Bazı kronik hastalıkların oluşumu ve sağlığı iyileştirici etkileri nedeniyle palmitoleik asit bir "lipokin" olarak düşünülmektedir. Yağ asidi şaperonları olan yağ asidi bağlayıcı protein 4 ve yağ asidi bağlayıcı protein 5 bulunmayan bir fare modeli kullanıldığında SCD-1 enzim aktivitesinin ve buna bağlı olarak adipoz dokuda palmitoleat konsantrasyonunun arttığı saptanmıştır. Bununla birlikte, palmitoleatın bazal seviyelerinin düşük konsantrasyonlarda olması, fizyolojik koşullara bağlı olarak bu konsantrasyonlarının değiştirilmesi, adipoz dokudan salınmasına rağmen karaciğerde hepatosteatozu baskılaması ve kaslarda insülin duyarlılığını artırması "lipokin" olarak kabul edilmesine yol açmıştır (11).

Yapılan kesitsel çalışmalarda palmitoleik asidin obezite, tip 2 diyabet, metabolik sendrom, nonalkolik yağlı karaciğer hastalığına sahip bireylerde sağlıklı bireylere kıyasla daha yüksek konsantrasyonlarda bulunduğu saptanmıştır $(6,8)$. Çin'de 50-70 yaş aralığındaki 3107 bireyle gerçekleştirilen bir çalışmada palmitoleik asidin eritrositlerdeki konsantrasyonunun metabolik sendrom ve tip 2 diyabet riski ile pozitif yönde ilişkili olduğu saptanmıştır $(17,18)$. Benzer şekilde 112 sağlıklı çocukta, plazma palmitoleik asit konsantrasyonları ile abdominal obezite arasında pozitif bir ilişki saptanmıştır (19). Aşağıda palmitoleik asidin bu hastalıklar ile ilişkisi açıklanmaktadır.

\section{Obezite}

Obezite, vücutta yağ dokusunun artışı ile karakterize olan multifaktöriyel bir hastalıktır. Çocuklarda ve yetişkinlerde yapılan çalışmalarda obez bireylerde palmitoleik asit seviyelerinin plazmada daha yüksek olduğu saptanmıştır (17-19). Abdominal adipozite ile palmitoleat düzeyleri arasında SCD1 aktivitesinin artmasına bağlı olarak pozitif yönlü korelasyon olduğu rapor edilmiştir. $\mathrm{Bu}$ nedenle, artmış palmitoleat konsantrasyonlarının, obezitenin patogenezinde rol oynayan önemli bir faktör olabileceği düşünülmektedir 
(11). Ancak yapılan bir başka prospektif çalışmada plazma trans-palmitoleat düzeyleri ile beden kütle indeksi (BKI) ve bel çevresi arasındaki korelasyon düşük bulunmuştur (20).

Palmitoleik asit takviyesinin obezitenin kontrolünde etkili olabileceği bazı çalışmalarda rapor edilmiştir. Yüksek yağlı diyetle beslenen farelerde $300 \mathrm{mg} / \mathrm{kg}$ palmitoleik asit takviyesinin 10 gün sonunda insülin duyarlılığını ve adipoz dokuda GLUT 4 seviyelerini modüle ederek glukoz alımını artırdığı saptanmıştır (21). Benzer şekilde yapılan bir başka hayvan çalışmasında da $2 \mathrm{~g} / \mathrm{kg}$ makademya fistığ 1 (haftada $3 \mathrm{kez} / 12$ hafta) ile palmitoleik asit suplemantasyonunun adipoz dokuda hipertropiyi ve inflamatuvar belirteçlerin düzeylerini azalttığ saptanmıştır (22). Ancak makademya fistığının palmitoleik asidin yanı sıra yüksek oleik asit düzeyleri içermesi de yapılan çalışmalarda palmitoleik asidin etkisini saptamayı zorlaştırdığı belirtilmektedir. Genç erişkinlerde, 1 gün boyunca daha yüksek palmitoleik asit alımı, gastrointestinal geçişi ve iştahı etkileyen gastrik yarı boşalma zamanını yavaşlatmaktadır (23). Benzer şekilde erkek sıçanlarda, palmitoleik asit ve bir TGpalmitoleat formunun verilmesi, artan kolesistokinin konsantrasyonları yoluyla besin alımını azaltmıştır. $\mathrm{Bu}$ nedenle, eksojen palmitoleat'in k1sa vadeli etkilerinin doygunluk hissini oluşturarak besin alımını azaltabileceği gösterilmektedir (24).

\section{Kardiyovasküler Hastalıklar}

Yapılan epidemiyolojik çalışmalar, dolaşımda bulunan palmitoleat düzeylerinin kolesterol metabolizmasında etkili olabileceğini göstermektedir (Tablo 1). Çin'de yapılan bir çalışmada plazma fosfolipitlerde bulunan palmitoleat seviyesinin düşük LDL kolesterol ile ilişkili olduğu rapor edilmiştir (25). Ancak yapılan bir çalışmada eritrosit membranında bulunan cis palmitoleat düzeylerinin koroner kalp hastalıkları riski ile ilişkili olduğu saptanmıştır (8). Ancak eritrositlerdeki palmitoleat konsantrasyonlarının doku ve plazmadaki palmitoleat konsantrasyonlarını yansıtmayacağı belirtilmektedir (26).

Yapılan bir çalışmada dislipidemili bireylere 30 gün süresince verilen $220,5 \mathrm{mg}$ cis-palmitoleat takviyesinin C-reaktif protein (CRP), trigliserit, LDL kolesterol düzeylerini düşürürken, HDL kolesterol düzeylerini artırdığı saptanmıştır (27). Benzer şekilde sağlıklı bireylerde 20 g makademya fistığının 3 hafta tüketiminin toplam kolesterol, LDL ve BKİ değerlerinde azalma sağladığı saptanmıştır (28). Ancak hiperkolesterolemik bireylerde 3 hafta süreyle palmitoleik asit (enerjinin $\% 18$ 'i), oleik asit (enerjinin \%50) ve palmitik asitten (enerjinin \%25) zengin diyetlerde beslenmesi sonucunda oleik asit tüketen gruba kıyasla palmitoleik asit tüketen grupta toplam kolesterol, LDL düzeyleri artarken, HDL kolesterol düzeylerinde azalma saptanmıştır (29).

Tablo 1. Palmitoleik asit takviyesinin kan kolesterol düzeyleri üzerine etkisi

\begin{tabular}{|c|c|c|c|c|}
\hline $\begin{array}{c}\text { Palmitoleik AsitTüketim } \\
\text { Düzeyi/Süre }\end{array}$ & Örneklem & Belirteçler & Sonuçların Özeti & Referans \\
\hline $\begin{array}{l}\text { Palmitoleik asit } \\
\text { grubu(Enerji \%18)/ oleik } \\
\text { asit }(\mathrm{E} \% 50) / \text { palmitik asit } \\
(\mathrm{E} \% 25) / 3 \mathrm{hafta}\end{array}$ & $\begin{array}{l}\text { Hiperkolesterolemik } \\
\text { bireyler }(n=34)\end{array}$ & $\begin{array}{l}\text { Toplam kolesterol, HDL, } \\
\text { LDL }\end{array}$ & $\begin{array}{l}\text { Palmitoleik asit grubunda } \\
\text { toplam kolesterol, LDL } \\
\text { seviyelerinde artı̧/ HDL } \\
\text { düzeylerinde azalma }\end{array}$ & (29) \\
\hline $\begin{array}{l}20 \text { g makademya } \\
\text { fist1 } \breve{g}_{1} / \text { Hindistan cevizi } \\
\text { yağ } / \text { tereyağ } 1 / 3 \text { hafta }\end{array}$ & $\begin{array}{l}\text { Sağlıklı bireyler } \\
(\mathrm{n}=71)\end{array}$ & $\begin{array}{l}\text { Toplam kolesterol, LDL ve } \\
\text { vücut ağırlığ1 }\end{array}$ & $\begin{array}{l}\text { Makademya fistığ } 1 \\
\text { grubunda toplam kolesterol, } \\
\text { LDL, vücut ağırlığ ve BKİ } \\
\text { değerlerinde azalma }\end{array}$ & (28) \\
\hline $\begin{array}{l}\text { Tipik Amerikan } \\
\text { diyeti/E\%15 MUFA içeren } \\
\text { diyet/E\%20 palmitoleik } \\
\text { asit } / 30 \text { gün }\end{array}$ & $\begin{array}{l}\text { Sağlıklı bireyler } \\
(\mathrm{n}=30)\end{array}$ & $\begin{array}{l}\text { Toplam kolesterol, HDL, } \\
\text { LDL }\end{array}$ & $\begin{array}{l}\text { Toplam kolesterol, LDL ve } \\
\text { HDL seviyelerinde azalma }\end{array}$ & (34) \\
\hline $\begin{array}{l}\text { Makademya fistığ } 1 \text { (40-90 } \\
\text { g/gün) /4 hafta }\end{array}$ & $\begin{array}{l}\text { Hiperkolesterolemik } \\
\text { erkek birey }\end{array}$ & $\begin{array}{l}\text { Toplam kolesterol, HDL, } \\
\text { LDL, müdahale öncesi ve } \\
\text { sonras1 plazma yağ asitleri } \\
\text { profili }\end{array}$ & $\begin{array}{l}\text { Toplam kolesterol, LDL } \\
\text { düzeylerinde azalma, } \\
\text { HDL ve plazma palmitoleik } \\
\text { asit, oleik asit seviyelerinde } \\
\text { artış }\end{array}$ & (35) \\
\hline $\begin{array}{l}\text { Makademya fistığ }(42.5 \\
\text { g/gün)/tipik Amerikan } \\
\text { diyeti/5 hafta }\end{array}$ & $\begin{array}{l}\text { Hiperkolesterolemik } \\
\text { bireyler }(n=25)\end{array}$ & $\begin{array}{l}\text { Toplam kolesterol, non- } \\
\text { HDL, LDL, plazma yağ } \\
\text { asitleri profili }\end{array}$ & $\begin{array}{l}\text { Toplam kolesterol, LDL, } \\
\text { non-HDL seviyelerinde } \\
\text { azalma, plazma palmitoleik } \\
\text { asit seviyelerinde artış. }\end{array}$ & (36) \\
\hline $\begin{array}{l}220 \mathrm{mg} \text { palmitoleik } \\
\text { asit/1000 mg MCT içeren } \\
\text { kapsül jel/30 gün }\end{array}$ & $\begin{array}{l}\text { Dislipidemi ve } \\
\text { sistemik } \\
\text { inflamasyonlu yetişkin } \\
\text { bireyler }(n=30)\end{array}$ & $\begin{array}{l}\text { Toplam kolesterol, HDL, } \\
\text { LDL, trigliserit, CRP }\end{array}$ & $\begin{array}{l}\text { CRP, HDL, trigliserit } \\
\text { seviyelerinde azalma, HDL } \\
\text { seviyelerinde artış }\end{array}$ & (27) \\
\hline
\end{tabular}




\section{Tip 2 Diyabet ve İnsülin Direnci}

İnsülin direnci, kronik hastalıkların temelinde yer alan ve insülinin periferik dokularda işlev gösterememesi ile karakterize bir durumdur. Yapılan hayvan çalışmalarında palmitoleik asidin endojen sentezi ve diyetle alımının insülin duyarlılığını artırabildiği gösterilmektedir (11, 30). Yapılan bir hayvan çalışmasında adipoz dokudan gelen palmitoleik asidin, kaslarda insülin duyarlılığını arttırdığ 1 ve yağ dokusunda monosit kemoatraktan protein 1 (MCP-1) ve tümör nekrozis faktör- $\alpha$ (TNF- $\alpha$ ) ekspresyonunu baskıladığı belirtilmiştir (11). Ayrıca, palmitoleik asidin, GLUT-4'ün plazma membranına translokasyonu yoluyla insülin direnci üzerinde olumlu etkilere sahip olduğu rapor edilmiştir (31). Hücresel çalışmalarda ise yüksek palmitatın yol açtığı endoplazmik retikulum stresini ve apoptozu önleyebildiği gösterilmiştir (32). Yüksek yağlı diyetle beslenen kontrol ve PPAR- $\alpha$ gen ifadesi durdurulmuş (knock out) farelere 14 gün süreyle $300 \mathrm{mg} / \mathrm{kg}$ palmitoleik asit takviyesinin insülin direncini ve interlökin-1 seviyelerini azalttığı, glukoz alımını uyardığı saptanmıştır (33). Benzer şekilde yapılan bir başka hayvan çalışmasında da obez-diyabetik farelerde hiperglisemi ve hipertrigliseridemiyi azalttığı, insülin duyarlılığını artırdığ 1 ve adipoz dokudan TNF- $\alpha$ salınımını azalttığı saptanmıştır (30). Bu çalışmalara ek olarak insanlarda yapılan epidemiyolojik çalışmalara bakıldığında ise plazma trans-palmitoleat düzeylerindeki her \%0.05'lik artışın tip 2 diyabet gelişimini \%28-32 oranında azaltacağı rapor edilmiştir (20). Ancak insan çalışmalarında palmitoleik asit takviyesi bulunan randomize kontrollü çalışmaya rastlanmamıştır.

\section{SONUÇ VE ÖNERİLER}

Palmitoleatın, obezite gelişimindeki rolü, karaciğer veya kardiyovasküler sağlığa olan katkısı henüz net olmamakla birlikte yüksek palmitoleat konsantrasyonlarıyla ilişkilendirilmiştir. Yapılan hayvan çalışmalarında, palmitoleik asidin artmış transkripsiyonel aktivite, geliştirilmiş insülin sinyali, enzimler ile sitokinlerin modülasyonu gibi çeşitli mekanizmalar aracılığı ile insülin duyarlılı̆̆ını geliştirebileceği gösterilmiş ancak insan çalışmalarında henüz kanıtlanamamıştır. Bununla birlikte yapılan hayvan çalışmaları ile insan çalışmaları arasında gözlenen tutarsızlıkların gerekçesi bilinmemektedir. $\mathrm{Bu}$ nedenle palmitoleatın farklı etnik kökenlere, yaşlara ve halihazırda bir kronik hastalığa sahip bireylerde olan etkilerini ve bu etkileri açıklamak için bu konuda yapılacak randomize kontrollü çalışmalara ihtiyaç bulunmaktadır.

Yazarların Katkıları: Fikir/Kavram: M.B., A.U.; Tasarım: M.B., A.U.; Literatür Taraması: M.B., A.U.; Makale Yazımı: M.B.; Eleştirel İnceleme: M.B., A.U.

\section{KAYNAKLAR}

1. World Health Organization [Internet]. Switzerland: Global status report on noncommunicable diseases [Updated: 2011; Cited 2020 January 7]. Available from:https://www.who.int/nmh/publications/ncd_repo rt2010/en/.

2. World Health Organization [Internet]. Switzerland: Global status report on noncommunicable diseases [Updated: 2014; Cited 2020 January 7]. Available from:http://www.who.int/nmh/publications/ncdstatus-report-2014/en/.

3. TC Sağlık Bakanlığg1. Türkiye'ye Özgü Besin ve Beslenme Rehberi. Yayın No: 1031. Ankara: Kayhan Ajans; 2016.

4. Food and Agriculture Organization of the United Nations. Fats and fatty acids in human nutrition Report of an expert consultation. FAO Food Nutr Pap. 2010; 91: 1-166.

5. World Health Organization [Internet]. Switzerland: Global atlas on cardiovascular disease prevention and control [Updated: 2011; Cited 2020 January 7]. Available from: http://www.who.int/cardiovascular_diseases/publicati ons/atlas_cvd/en/.

6. Hodson L, Karpe F. Is there something special about palmitoleate? Curr Opin Clin Nutr Metab Care. 2013; 16(2): 225-31.

7. Gong J, Campos H, McGarvey S, Wu Z, Goldberg R, Baylin A. Adipose tissue palmitoleic acid and obesity in humans: does it behave as a lipokine? Am J Clin Nutr. 2011; 93(1):186-91.

8. Djousse L, Matthan NR, Lichtenstein AH, Gaziano JM. Red blood cell membrane concentration of cispalmitoleic and cis-vaccenic acids and risk of coronary heart disease. Am J Cardiol. 2012;110(4): 539-44.

9. Walker CG, Browning LM, Stecher L, West AL, Madden J, Jebb SA, et al. Fatty acid profile of plasma NEFA does not reflect adipose tissue fatty acid profile. Br J Nutr. 2015; 114(5): 756-62.

10. Walker CG, West AL, Browning LM, Madden J, Gambell JM, Jebb SA, et al. The pattern of fatty acids displaced by epa and dha following 12 months supplementation varies between blood cell and plasma fractions. Nutrients. 2015; 7(8): 6281-93.

11. Cao H, Gerhold K, Mayers JR, Wiest MM, Watkins SM, Hotamisligil GS. Identification of a lipokine, a lipid hormone linking adipose tissue to systemic metabolism. Cell. 2008; 134(6): 933-44.

12. Frigolet ME, Gutierrez-Aguilar R. The Role of the Novel Lipokine Palmitoleic Acid in Health and Disease. Adv Nutr. 2017; 8(1): 173-81.

13. Fatima T, Snyder CL, Schroeder WR, Cram D, Datla R, Wishart D, et al. Fatty acid composition of developing sea buckthorn (Hippophae rhamnoides L.) berry and the transcriptome of the mature seed. PLoS One. 2012; 7(4): 1-18

14. Micha R, King IB, Lemaitre RN, Rimm EB, Sacks F, Song $\mathrm{X}$, et al. Food sources of individual plasma phospholipid trans fatty acid isomers: the Cardiovascular Health Study. Am J Clin Nutr. 2010; 91(4): 883-93.

15. Goeransson. G. The metabolism of fatty acids in the rat palmitoleic acid. Acta Physiol Scand. 1965; 63: 428-33.

16. Jaudszus A, Kramer R, Pfeuffer M, Roth A, Jahreis G, Kuhnt K. trans Palmitoleic acid arises endogenously from dietary vaccenic acid. Am J Clin Nutr. 2014; 99(3): 431-5.

17.Zong G, Ye X, Sun L, Li H, Yu Z, Hu FB, et al. Associations of erythrocyte palmitoleic acid with adipokines, inflammatory markers, and the metabolic 
syndrome in middle-aged and older Chinese. Am J Clin Nutr. 2012; 96(5): 970-6.

18. Zong G, Zhu J, Sun L, Ye X, Lu L, Jin Q, et al. Associations of erythrocyte fatty acids in the de novo lipogenesis pathway with risk of metabolic syndrome in a cohort study of middle-aged and older Chinese. Am J Clin Nutr. 2013; 98(2): 319-26.

19. Okada T, Furuhashi N, Kuromori Y, Miyashita M, Iwata F, Harada K. Plasma palmitoleic acid content and obesity in children. Am J Clin Nutr. 2005; 82(4): 747-50.

20. Mozaffarian D, Cao H, King IB, Lemaitre RN, Song $\mathrm{X}$, Siscovick DS, et al. Trans-palmitoleic acid, metabolic risk factors, and new-onset diabetes in U.S. adults: a cohort study. Ann Intern Med. 2010; 153(12): 790-9.

21. Bolsoni-Lopes A, Festuccia WT, Chimin P, Farias TS, Torres-Leal FL, Cruz MM, et al. Palmitoleic acid (n-7) increases white adipocytes GLUT4 content and glucose uptake in association with AMPK activation. Lipids Health Dis. 2014; 13: 199-10.

22. Lima EA, Silveira LS, Masi LN, Crisma AR, Davanso MR, Souza GI, et al. Macadamia oil supplementation attenuates inflammation and adipocyte hypertrophy in obese mice. Mediators Inflamm. 2014; 870634; 1-9.

23. Markey O, McClean CM, Medlow P, Davison GW, Trinick TR, Duly E, et al. Effect of cinnamon on gastric emptying, arterial stiffness, postprandial lipemia, glycemia, and appetite responses to high-fat breakfast. Cardiovasc Diabetol. 2011; 10: 78-7.

24. Yang ZH, Takeo J, Katayama M. Oral administration of omega-7 palmitoleic acid induces satiety and the release of appetite-related hormones in male rats. Appetite. 2013; 65: 1-7.

25. Foryst-Ludwig A, Kreissl MC, Benz V, Brix S, Smeir E, Ban Z, et al. Adipose Tissue Lipolysis Promotes Exercise-induced Cardiac Hypertrophy Involving the Lipokine C16:1n7-Palmitoleate. J Biol Chem. 2015; 290(39): 23603-15.

26. Arab L. Biomarkers of fat and fatty acid intake. J Nutr. 2003; 133 Suppl 3(3): 925-32.

27. Bernstein AM, Roizen MF, Martinez L. Purified palmitoleic acid for the reduction of high-sensitivity C-reactive protein and serum lipids: a double-blinded, randomized, placebo controlled study. J Clin Lipidol. 2014; 8(6): 612-7.

28. Hiraoka-Yamamoto J, Ikeda K, Negishi H, Mori M, Hirose A, Sawada S, et al. Serum lipid effects of a monounsaturated (palmitoleic) fatty acid-rich diet based on macadamia nuts in healthy, young Japanese women. Clin Exp Pharmacol Physiol. 2004; 31 Suppl 2: 37-8.

29. Nestel P, Clifton P, Noakes M. Effects of increasing dietary palmitoleic acid compared with palmitic and oleic acids on plasma lipids of hypercholesterolemic men. J Lipid Res. 1994; 35(4): 656-62.

30. Curb JD, Wergowske G, Dobbs JC, Abbott RD, Huang B. Serum lipid effects of a highmonounsaturated fat diet based on macadamia nuts. Arch Intern Med. 2000; 160(8): 1154-8.

31. Garg ML, Blake RJ, Wills RB. Macadamia nut consumption lowers plasma total and LDL cholesterol levels in hypercholesterolemic men. J Nutr. 2003; 133(4): 1060-3.

32. Griel AE, Cao Y, Bagshaw DD, Cifelli AM, Holub B, Kris-Etherton PM. A macadamia nut-rich diet reduces total and LDL-cholesterol in mildly hypercholesterolemic men and women. J Nutr. 2008; 138(4): 761-7.

33. Dimopoulos N, Watson M, Sakamoto K, Hundal HS. Differential effects of palmitate and palmitoleate on insulin action and glucose utilization in rat L6 skeletal muscle cells. Biochem J. 2006; 399(3): 473-81.

34. Erbay E, Babaev VR, Mayers JR, Makowski L, Charles KN, Snitow ME, et al. Reducing endoplasmic reticulum stress through a macrophage lipid chaperone alleviates atherosclerosis. Nat Med. 2009; 15(12): 1383-91.

35. Souza CO, Teixeira AA, Lima EA, Batatinha HA, Gomes LM, Carvalho-Silva M, et al. Palmitoleic acid (n-7) attenuates the immunometabolic disturbances caused by a high-fat diet independently of PPARalpha. Mediators Inflamm. 2014; 2014: 582197.

36. Yang ZH, Miyahara H, Hatanaka A. Chronic administration of palmitoleic acid reduces insulin resistance and hepatic lipid accumulation in KK-Ay Mice with genetic type 2 diabetes. Lipids Health Dis. 2011; 10: 120-8. 